\title{
Propeller Flaps for Reconstructing Leg and Foot Defects: The Relation between Flap Length and the Incidence of Ischemia
}

\author{
SHOEIB M.A., M.D.; GAMAL YOUSSEF, M.D.; AHMED GABER, M.D.; AHMED SABER, M.Sc. and \\ EMAD GOMHA, M.D.
}

The Department of Plastic Surgery, Sohag University Hospital, Sohag, Egypt

\begin{abstract}
Background: Reconstruction of soft tissue defects in the leg and the foot remains challenging. Anatomical constraints limit the options available for reconstructing complex defects especially lower third of leg. Perforator propeller flaps are raising interest in reconstructive surgery of the limbs. We present our experience with perforator propeller flaps for reconstruction of soft tissue defects in leg and foot with an emphasis on the safe limit of a perforator flap in the lower limb.
\end{abstract}

Methods: The study was carried prospectively and 32 patients with leg or foot defects treated with various perforator propeller flaps (both elective as well as emergency) were included in the study. A hand-held ultrasound Doppler was used pre-operatively and intraoperatively to detect the perforator vessels.

Results: Out of the 32 cases, we witnessed total flap loss in one and distal necrosis in 6 cases. In 4 of them the flaps lengths were more than one third of the limb length. 8 patients had minor complications which included congestion, infection or graft loss.

Conclusion: Perforator flaps may represent a good alternative to the free flaps in the areas were other local reconstructive procedures are not possible. This is a versatile technique and with decreased donor site morbidity limited to a single body area. There is a specific like to like soft tissue replacement leading to a better cosmetic and reconstructive outcome. The main drawback of the perforator flaps however is the higher risk of venous congestion. The incidence of distal necrosis increases with flap length more than one third of the limb provided other factors affecting flap vitality are constant.

Key Words: Perforator flap - Propeller flap - Lower limbReconstruction.

\section{INTRODUCTION}

Plastic surgery is a constant battle between blood supply and beauty. The end result of a reconstructive procedure is primarily attributable to the stability of the vascular component, which is fundamental in that it ensures survival and proper functioning of tissues that have been transferred to the recipient site [1]. The lower limb has always been known for poor wound healing and, since the first steps of the plastic surgery, as a scarce source of flap for reconstruction. Soft tissue reconstruction of the lower limb is hence, challenging. Due to limited mobility and a paucity of overlying skin, even small soft tissue defects of the lower limb generally need flap coverage [2]. Before the introduction of microsurgery, surgeons had few reconstructive options such as local flaps (random skin flaps, muscular or musculocutancous flaps) and performed cross legs, immobilizing the limbs for weeks [3]. A random pattern flap has an indistinct perfusion pattern and is limited in size and mobility [4].

Musculocutaneous flaps and muscle flaps with skin grafts such as from the gastrocnemius, soleus, and tibialis anterior can be used in the proximal and middle thirds of a pretibial defect [5]. Unfortunately, the area least well served by these muscle flaps is the lower third of the leg.

The fasciocutaneous flap reported by Ponten showed that long narrow flaps could be safely raised below the knee as long as the deep fascia was included [6].

Ponten's flaps were not based on specific perforators and therefore could not be islanded. Free micro vascular transfer is an answer to most of the difficult reconstructions but it is time consuming, requires microsurgical facility and expertise. After a long evolution of the reconstructive methods, the reappraisal of the works of Manchot and Salmon by Taylor and Palmer opened the era of perforator flaps. This era began in 1989, when Koshima and Soeda, and separately Kroll and Rosenfield described.

The first applications of such flaps. Improvement in the anatomical knowledge on cutaneous, 
subcutaneous, and intramuscular vessels originating from major vascular axis of the limbs has allowed development of several types of perforator flaps, which today are commonly employed in clinical practice [7-9]. With the development of perforator flaps newer and more reliable flaps have become available for lower limb reconstruction [10]. According to the Gent consensus, these flaps are composed of skin and subcutaneous fat skeletonized on perforators arising from deep vascular systems to rotate as a propeller up to 180 degrees [11]. Although perforator flaps technique requires microsurgical dissection, it does not require vascular suturing and can thus be defined a microsurgical non micro vascular flap as reported by Georgescu et al., [12].

\section{MATERIAL AND METHODS}

This study was conducted prospectively from March 2017 to March 2018 in the Department of Plastic and Reconstructive Surgery of Sohag University Hospital, Egypt. 32 patients with leg or foot defects treated with various perforator propeller flaps (both elective as well as emergency) during this period were included in the study. A written informed consent was sought from each patient included in the study.

The etiology, site, size and characteristics of the defect and surrounding area were analyzed. In designing the flaps, the vascular axes and the distribution of the perforators which could sustain them were taken into consideration. A hand-held Ultrasound Doppler was used pre-operatively.

And intraoperatively to detect perforator vessels in the donor site area. Perforator artery selection before flap harvesting was based on vessel size and distance to the area of the defect. Once the perforator was identified, the flap was designed around the perforator or perforators according to the location and size of the defect. The dimensions of the flap were based upon the size of defect and the movement of the flap, taking into account the need to avoid excessive tension on the margins of the flap during suturing. The operations were performed using magnification loupes $(3.5 \mathrm{x})$ and microsurgical instruments. A tourniquet was inflated without prior exsanguination. This maneuver facilitates identification of perforators as they remain filled with the blood. An exploratory incision along the margin of flap was made keeping the position of marked perforator in mind. The incision is made through the skin, subcutaneous tissue, deep fascia (sub-fascial approach) and the perforator vessel is directly visualized. The incision is initially always made from one side of the flap only to properly identify and assess the caliber of the perforator. If the perforator previously identified by Doppler is not adequate, we looked for another suitable perforator and the flap design was modified accordingly. Careful and meticulous dissection was done in a blunt way isolating the perforator. Usually the perforator had to be dissected for several centimeters to allow easier rotation or advancement. Pedicle traction during flap harvesting and positioning was avoided.

Adequate release of all fascial strands around the perforator and dissection around the perforator in intermuscular or intramuscular plane to gain additional length were then carried out. This facilitates rotation of flap without kinking the perforator. After deflation of the tourniquet, hemostasis was performed and viability of flap was evaluated. Perfusion was checked before flap rotation by waiting a few minutes and irrigating with lukewarm saline solution in order to promote microcirculation recovery. The flap was then rotated on its perforator to varying degrees and inset into the defect after ensuring the viability and rechecking the vascularity while in desired position. Carefully positioned drains were then applied at the end of the procedure in some patients according to need. Drains were usually removed after $24 \mathrm{hrs}$. Bandaging was soft, to avoid compression over the flap, and the limb was held in an elevated position. A window was left uncovered for monitoring of colour and temperature without bandage removal. The donor sites in most of the cases were grafted, but primarily closed in few cases. Post-operative the flaps were monitored. The parameters monitored included colour, temperature, margins, congestion, epidermal shrinking, or blistering.

\section{RESULTS}

Detailed description of outcome results and complications is reported in (Table 1). The flaps in all cases were propelled to the defects with degrees ranging from 90 to 180 . Figs. (1-5) shows few index cases.

9 cases in our series developed complications. In one of them, the vascularity of the flap was so compromised intraoperatively and it was replaced by muscle flap and split thickness skin graft. 6 cases developed distal flap necrosis following congestion. Venous congestion occurred in another case, but managed conservatively and resolved spontaneously. Wound infection occurred in 3 cases out of the nine complicated and the graft lost in 2 of them and needed to be regrafted again. The flaps with partial necrosis had been debrided and one 
case needed a split thickness skin graft and in two cases, the wound healed by secondary intention. 10 cases in our study had flaps lengths exceeding one third of the limb. Distal necrosis occurred in 4 of them $(12.5 \%)$. The odds ratio calculated was
4.4, which means that there is 4.4 times more chance that a local perforator flap will necrose if it is more than one-third of the limb length as compared to a flap which is less than one-third of the limb length (Table 2).

Table (1): Clinical details of patients.

\begin{tabular}{|c|c|c|c|c|c|c|c|c|c|}
\hline $\begin{array}{l}\text { Case } \\
\text { no. }\end{array}$ & Age & Sex & Etiology & Site of defect & $\begin{array}{l}\text { Perforator flap } \\
\text { source artery }\end{array}$ & $\begin{array}{l}\text { Flab } \\
\text { size }\end{array}$ & $\begin{array}{l}\text { Duration } \\
\text { of the } \\
\text { procedure } \\
\text { (hrs) }\end{array}$ & $\begin{array}{l}\text { Donor site } \\
\text { management }\end{array}$ & Complications \\
\hline $1-$ & 32 & $\mathrm{M}$ & - RTA & - Left lateral malleolus & - Peroneal a. & $20 / 7 \mathrm{~cm}$ & 2.3 & - STG & - Nil. \\
\hline $2-$ & 55 & M & - RTA & - Lt leg (middle third) & - Posterior Tibial a. & $13 / 4 \mathrm{~cm}$ & 2.5 & $\begin{array}{l}\text { - Primary } \\
\text { closure. }\end{array}$ & - Total flap loss. \\
\hline $3-$ & 40 & $\mathrm{~F}$ & - Hemangioma & - RT leg (lower third) & - Peroneal a. & $16 / 6 \mathrm{~cm}$ & 2 & - STG & - Nil. \\
\hline 4- & 35 & $\mathrm{M}$ & - RTA & - LT leg (middle third) & - Posterior Tibial a. & $23 / 5 \mathrm{~cm}$ & 2.3 & - STG & $\begin{array}{l}\text { - Congestion }+ \text { distal } \\
\text { necrosis }+ \text { loss of part of } \\
\text { the graft. }\end{array}$ \\
\hline $5-$ & 9 & $\mathrm{M}$ & - RTA & - LT foot & - Posterior Tibial a. & $20 / 5 \mathrm{~cm}$ & 2.5 & $\begin{array}{l}\text { - Primary } \\
+ \text { STG }\end{array}$ & - Nil. \\
\hline $6-$ & 37 & M & - RTA & - RT Tendo-Achilles & - Medial planter a. & $9 / 4 \mathrm{~cm}$ & 1.5 & - STG & - Nil. \\
\hline 7- & 22 & M & - Fall from hight & - RT Tendo-Achilles & - Medial planter a. & $10 / 4 \mathrm{~cm}$ & 2 & - STG & - Nil. \\
\hline 8- & 18 & $\mathrm{~F}$ & - Angio lipoma & - LT medial malleolus & - Posterior Tibial a. & $12 / 5 \mathrm{~cm}$ & 2.3 & - STG & - Nil. \\
\hline 9- & 28 & $\mathrm{M}$ & - Fall from hight & - RT lateral malleolus & - Peroneal a. & $22 / 6 \mathrm{~cm}$ & 3 & - STG & $\begin{array}{l}\text { - Congestion }+ \text { distal } \\
\text { necrosis. }\end{array}$ \\
\hline $10-$ & 30 & M & - RTA & - RT leg (distal third) & - Posterior Tibial a. & $12 / 5 \mathrm{~cm}$ & 2.5 & $\begin{array}{l}\text { - } \text { Primary } \\
+ \text { STG }\end{array}$ & $\begin{array}{l}\text { - Congestion + Infection } \\
+ \text { graft loss. }\end{array}$ \\
\hline $11-$ & 42 & M & - RTA & - LT leg (distal third) & - Posterior Tibial a. & $7 / 4 \mathrm{~cm}$ & 3 & - STG & - Nil. \\
\hline $12-$ & 21 & $\mathrm{M}$ & - RTA & - RT foot (heel) & - Posterior Tibial a & $23 / 4 \mathrm{~cm}$ & 2.3 & $\cdot$ STG & $\begin{array}{l}\text { - Congestion + distal } \\
\text { necrosis. }\end{array}$ \\
\hline $13-$ & 32 & $\mathrm{M}$ & - RTA & - RT foot (heel) & - Medial planter a. & $6 / 3 \mathrm{~cm}$ & 1.5 & - STG & - Nil. \\
\hline $14-$ & 25 & M & - RTA & - RT leg (middle third) & - Posterior Tibial a & $10 / 5 \mathrm{~cm}$ & 1.5 & - STG & - Nil. \\
\hline $15-$ & 32 & M & - RTA & - RT leg (middle third) & - Posterior Tibial a. & $8 / 4 \mathrm{~cm}$ & 2 & - STG & - Nil. \\
\hline 16- & 21 & M & - RTA & - RT leg (distal third) & - Posterior Tibial a. & $12 / 4 \mathrm{~cm}$ & 2 & - STG & - Nil. \\
\hline $17-$ & 30 & $\mathrm{~F}$ & - Osteomylitis & - Lt leg (middle third) & - Posterior Tibial a. & $11 \mid 4$ & 2 & - STG & $\begin{array}{l}\text { - Congestion + distal } \\
\text { necrosis. }\end{array}$ \\
\hline $18-$ & 25 & M & - RTA & - RT medial malleolus & - Posterior ataibial a. & $13 \mid 6$ & 1.45 & - STG & \\
\hline 19- & 28 & M & - FFH & - Distal third Lt leg & - Posterior Tibial a. & $10 / 4$ & 2 & - STG & \\
\hline $20-$ & 32 & M & - RTA & - RT lateral malleolus & - Peroneal a. & $14 \mid 5$ & 2.5 & - STG & $\begin{array}{l}\text { - Congestion + distal } \\
\text { necrosis. }\end{array}$ \\
\hline $21-$ & 35 & M & - Firearm injury & - Middle third Lt leg & - Peroneal a. & $10 \mid 4$ & 2 & - STG & \\
\hline $22-$ & 16 & $\mathrm{~F}$ & - RTA & - RT lateral malleolus. & - Peroneal a. & $15 \mid 6$ & 2.15 & - STG & \\
\hline $23-$ & 33 & M & - Neuropathic ulcer. & - LT heal & - Medial planter a. & $8 \mid 4$ & 2 & - STG & \\
\hline 24- & 25 & M & - RTA & - Middle third LT leg & - Posterior Tibial a. & $9 \mid 4$ & 2.5 & - STG & \\
\hline $25-$ & 44 & M & - RTA & - Dorsum of Rt ankle & - Posterior Tibial a. & $15 \mid 5$ & 3 & - STG & \\
\hline 26- & 24 & M & - Neuropathic ulcer & - RT Heal & - Medial planter a. & $8 \mid 3$ & 1.5 & - STG & - Wound infection. \\
\hline $27-$ & 27 & M & - RTA & - LT Heal & - Medial planter a. & $5 \mid 4$ & 1.5 & - STG & \\
\hline \multirow[t]{2}{*}{$\begin{array}{l}28- \\
29-\end{array}$} & 40 & $\mathrm{~F}$ & - RTA & - Distal third RT leg & - Posterior Tibial a. & $7 \mid 4$ & 2 & - STG & $\begin{array}{l}\text { - Congestion + distal } \\
\text { necrosis. }\end{array}$ \\
\hline & 25 & $\mathrm{M}$ & - RTA & - LT Tendo-Achilles & - Posterior Tibial a. & $10 \mid 5$ & 2.15 & - STG & \\
\hline $30-$ & 39 & $\mathrm{~F}$ & $\cdot \mathrm{FFH}$ & - RT Tendo-Achilles & - Posterior Tibial a. & $11 \mid 5$ & 2.5 & - STG & \\
\hline $31-$ & 26 & M & - RTA & - LT Heal & - Medial planter a. & $6 / 3$ & 1.5 & - STG & \\
\hline $32-$ & 40 & $\mathrm{~F}$ & - Angio lipoma & - Distal third LT leg & - Posterior Tibial a. & $8 / 4$ & 2 & $\begin{array}{l}\text { - Primary } \\
\text { closure + } \\
\text { small STG }\end{array}$ & \\
\hline
\end{tabular}


Table (2):

\begin{tabular}{lccc}
\hline $\begin{array}{l}\text { Percentage of flap } \\
\text { Compared to leg length }\end{array}$ & $\begin{array}{l}\text { Total } \\
\text { flaps }\end{array}$ & Necrosis & Percentage \\
\hline < one third of leg length & 12 & 2 & 6.25 \\
> one third of leg length & 10 & 4 & 12.5 \\
\hline Total & 32 & 6 & 18.75 \\
\hline
\end{tabular}
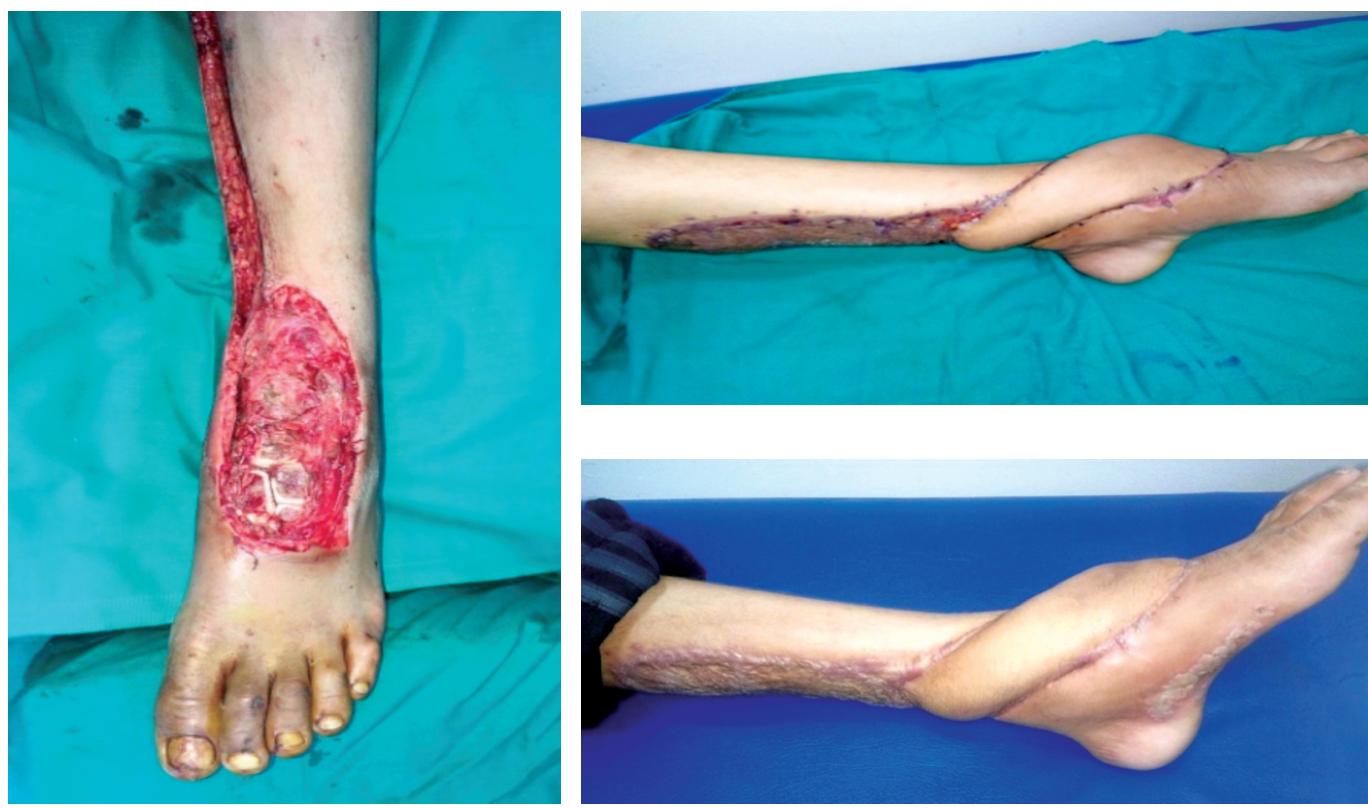

Fig. (1): Posterior tibial artery perforator propeller flap for covering a defect on dorsum of left foot.
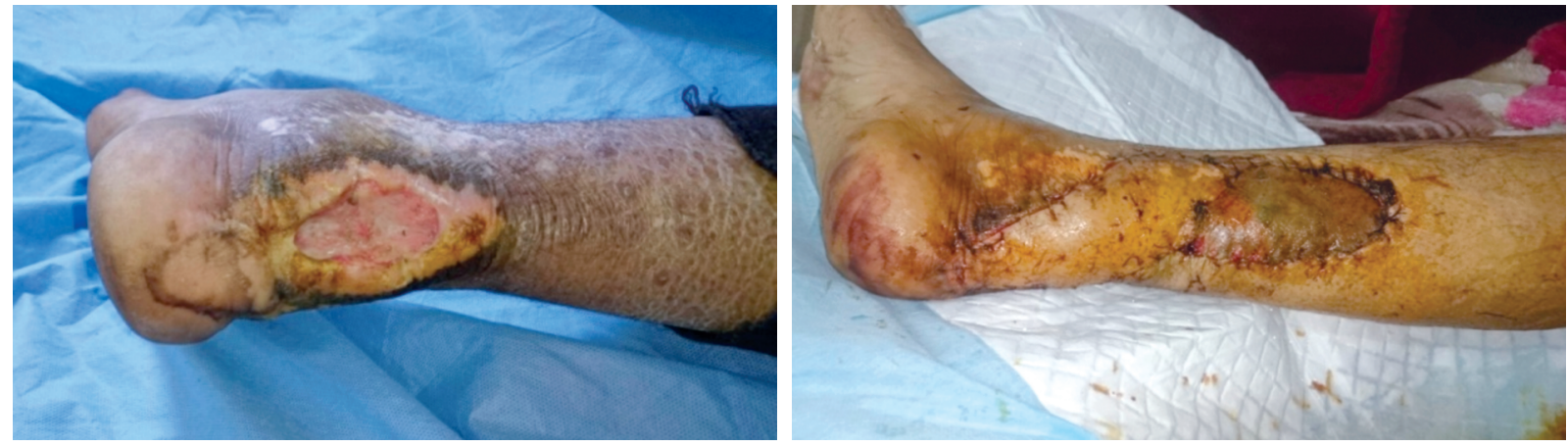

Fig. (2): Posterior tibial artery perforator flap for covering exposed Tendo-Achilles.
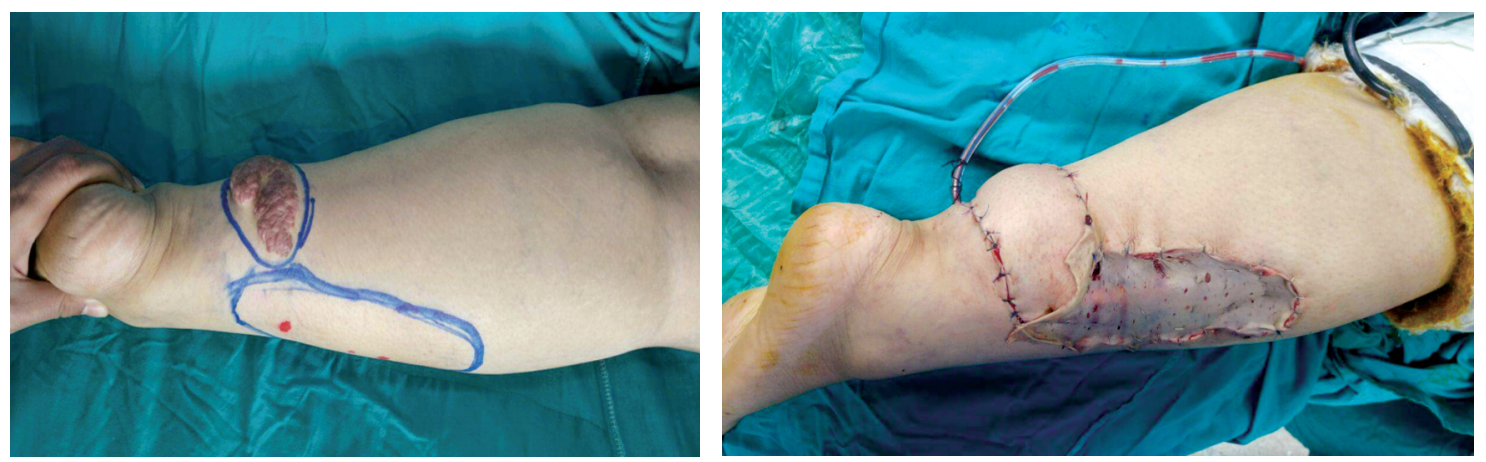

Fig. (3): Hemangioma excision and reconstruction by peroneal artery perforator flap. 

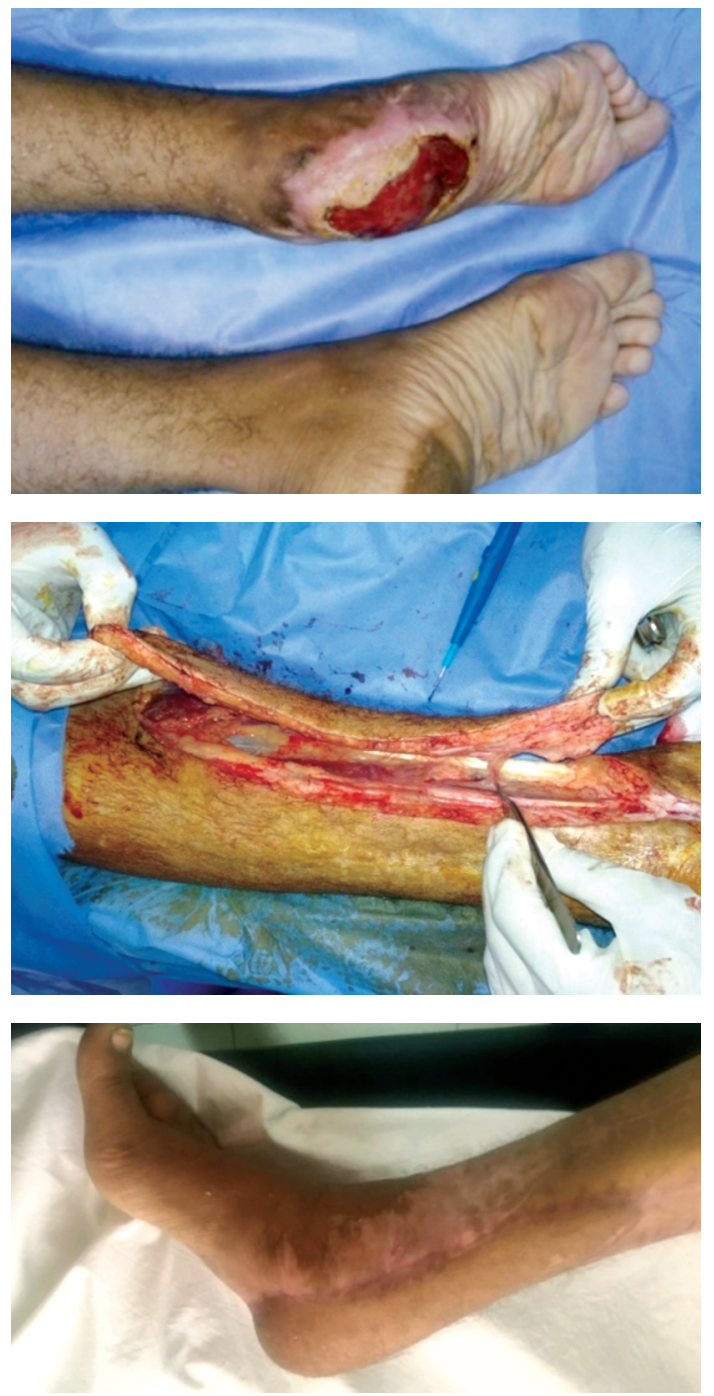

Fig. (4): Posterior tibial artery perforator flap for covering a heal defect.

\section{DISCUSSION}

The lower limb has always been known for poor wound healing and soft tissue reconstruction of the lower limb is challenging. The ideal reconstruction technique for both simple and complex defects of the lower limb should replace like to like tissue, minimize donor-site morbidity, preserve main vascular trunks, and reduce operating and hospitalization time. Perforator based flaps meet most of these requirements. The development of perforator flaps in reconstructive microsurgery has been facilitated by improved knowledge of the arterial basis of flap perfusion. The subdermic vascular network is particularly rich and allows the harvesting of thin skin flaps. One single perforator vessel located in an eccentric position in
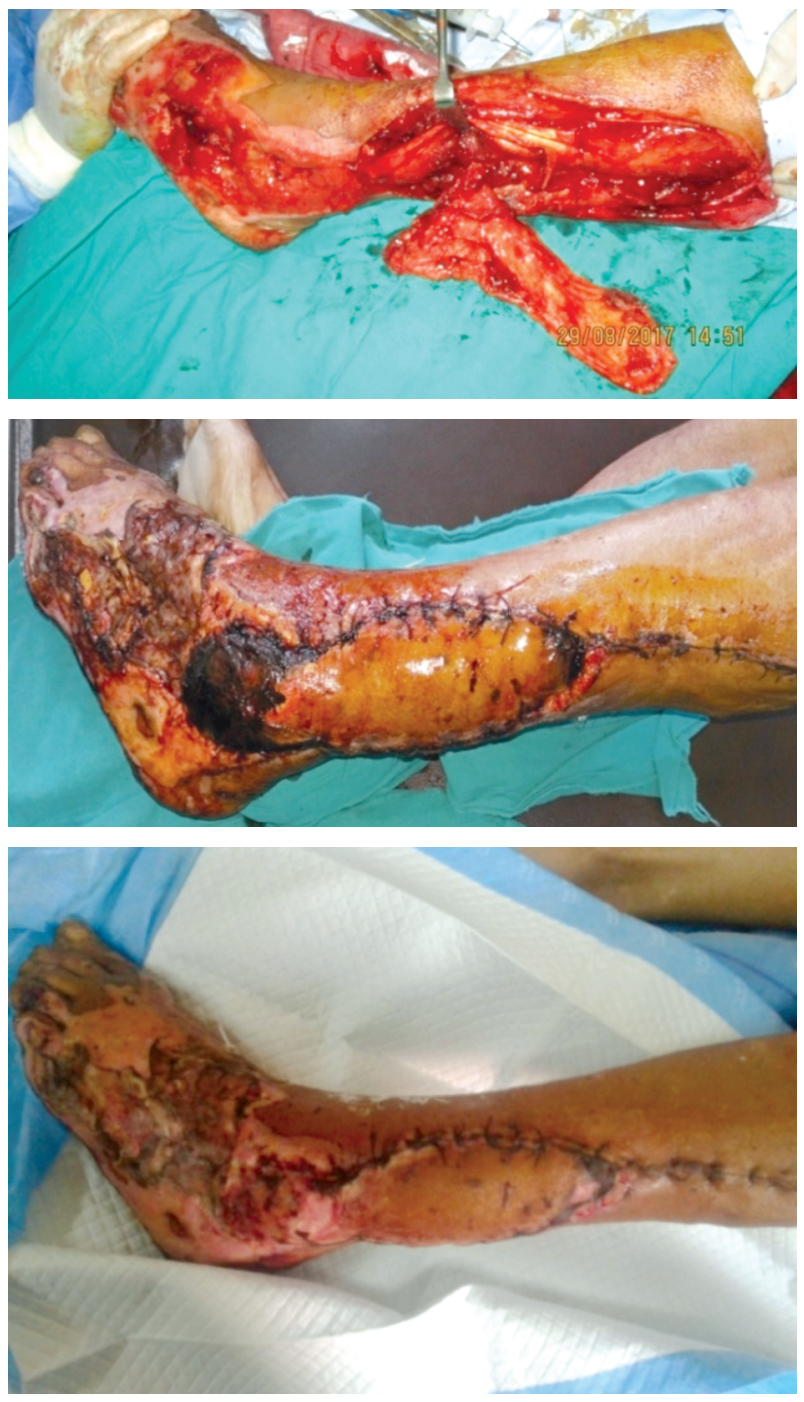

Fig. (5): Traumatic raw area on outer aspect of left foot and exposed lateral malleolus reconstructed by a peroneal artery perforator propeller flap for the malleolus and a split thickness skin graft for the foot. Ischemia and debridment of the distal part.

relation to a skin paddle may support a large skin area thanks to the opening of potential vascular territories, which move to the peripheral border of the flap [11]. The process of vascular adoption is promoted by the increase of blood pressure, which occurs in the perforator artery after closure of subcutaneous and intramuscular branches during flap harvesting. One of the main characteristics of perforator flaps is their versatility, as the flap may be selected on the perforator artery according to defect type [12].

Twelve patients (75\%) in our study had soft tissue loss following road traffic accident which has shown an increase in recent years and the usual mode was motor bike accident. Other etiologies in our series included fall from height $(12.5 \%)$ and 
oncological resections $(12.5 \%)$. The reason for road traffic accidents accounting for most of the cases in the study can be attributed to a tremendous increase in the number of vehicles and nowadays road traffic accidents are predicted to be the third leading contributor to the global burden of disease.

Fourteen patients $(87.5 \%)$ in the study were males and only two patients $(12.5 \%)$ were females with male:female ratio is $7: 1$ and this can be explained by the fact that males in Egypt are mainly responsible for working and spending, so they are more vulnerable to trauma than females. Ages of the patients ranged from 9 to 55 years with the mean age is about 30 years and this also can be attributed to the past reason.

The most common site of reconstruction in our study was the distal third of leg which constituted $25 \%$ of cases. In our department free tissue transfer was the mainstay method of reconstructing defects in lower third of leg, but the encouraging results obtained from using perforator propeller flaps will change this policy. The fact that lower third of leg is a difficult site for reconstruction with limited options, perforator flaps have been recommended by several clinical studies reported on the application of perforator based local flaps in lower-limb reconstruction [9,13-15].

The size of perforator flap that can be safely harvested has always been a point of argument and bone of contention for plastic surgeons all over the world. The length of the flap in our study ranged from 6 to $23 \mathrm{~cm}$ and the width ranged from 3 to $7 \mathrm{~cm}$. The maximum size of flap harvested was $23 \mathrm{X} 5 \mathrm{~cm}^{2}$ and used for covering a defect in middle third of left leg following a road traffic accident. The large flap territory can be raised on a single perforator due to extensive axial communications between the perforators within the flap. Hyper perfusion in a perforator allows the capture of multiple adjacent perforasomes through direct and indirect lining vessels [16].

Panse NS et al., in their study made an attempt to define the safe extent of local perforator flap for lower limb reconstruction by comparing it with the limb length of the patient and concluded that there is a six times more chance that a local perforator flap will necrose if it is more than one-third of the limb length as compared to a flap which is less than one-third of the limb length.

Taylor et al., in their study used computed tomography angiography to locate vessels and detect the anatomical territories of the adjacent perforators.
10 cases in our study had flaps lengths more than one third of the limb, 4 of them had distal necrosis $(12.5 \%)$, but the other 6 cases experienced no ischemia Fig. (1). This supports the results obtained by Panse NS et al., to some extent, but it is pertinent to mention here that there is still no standardization or reference for safe limit of a perforator flap because there are multiple other factors which can influence the outcome of the perforator flap like size of the particular perforator and its ability to overcome the particular angiosome, distance between two perforators, associated vascular disease, trauma zone, posttraumatic vascular disease of the vessel and the perforator, spasm of the perforator at that particular time because of systemic or surrounding temperature or handling of tissues. It is because of multiple factors that it is difficult to predict with certainty the safe limit of a perforator propeller flap in lower extremity reconstruction.

In our study, we could raise a variety of perforator propeller flaps based on posterior tibial artery [20], peroneal artery [6] and in 6 cases the flaps had raised on medial planter artery itself and propelled to cover heal defects.

The operative time in most of studies ranges between 2 to 3 hours. Average duration of surgery in our series was $2.30 \mathrm{hrs}$, with maximum duration of $3.15 \mathrm{hrs}$ and minimum duration of $1.30 \mathrm{hrs}$. This makes the perforator flap reconstruction a preferred option for patients with co-morbidities who might not be good candidates for longer duration surgeries.

In our series, the pedicle length of perforator flaps ranged from a minimum of $1 \mathrm{~cm}$ to a maximum of $2.5 \mathrm{~cm}$. The vascularity of the flap which had a pedicle length of $1 \mathrm{~cm}$ was not promising and removed intra operatively to be replaced by a muscle flap. This small pedicle could be twisted during rotation. Perforator flaps with a pedicle length more than $2 \mathrm{~cm}$ were less liable to congestion and ischemia. The axial propeller flaps in the study had a pedicle length of 5 or $6 \mathrm{~cm}$ and experienced no congestion nor ischemia.

As regard the complications, we witnessed partial flap necrosis in three cases following venous congestion. One case had a flap congestion that resolved without ischemia. The main reason for flap loss has been attributed to venous congestion which can occur due to kinking of the vein following flap rotation because of thinner wall as compared to that of the artery. 
In one case, the vascularity of the flap was so compromised intra operative and it was replaced by muscle flap and split thickness skin graft, so in using perforator propeller flaps we should consider another method of reconstruction as a plan B to be used if there is in adequate perforators.

\section{Conclusion:}

Over the last years, perforator propeller flaps provided a precious therapeutic option for the reconstruction of soft tissue defects at the lower limb level even becoming the first choice in case of soft tissue losses of small or medium dimensions provided a good preoperative planning as regards the perforator condition and the flap dimensions. This is a versatile technique and with decreased donor site morbidity limited to a single body area. These flaps do not involve sacrifice of any of the main arteries. They can cover very distal defects of the leg. There is a specific like to like soft tissue replacement leading to a better cosmetic and reconstructive outcome. There is 4.4 times increase in the risk of distal necrosis when the flap length is more than one third of the limb, but other factors can influence the fate of the flap. So finally, we can say that it is better to choose another reconstructive method if the flap length designed is more than one third of limb length.

\section{REFERENCES}

1- Gillies H.D. and D.R. Millard: The principles and art of plastic surgery. Vol. 2. 1957: Little, Brown, 1957.

2- Lister G. and L. Scheker: Emergency free flaps to the upper extremity. Journal of Hand Surgery, 13 (1): p. 22 28, 1988.

3- Jayes P.H.: Cross-leg flaps: A review of sixty cases. British Journal of Plastic Surgery, 3: p. 1-5, 1950.

4- Quaba O. and Quaba A.: Pedicled perforator flaps for the lower limb. In Seminars in Plastic Surgery, Thieme Medical Publishers, 2006.
5- Fayman M.S., et al.: The distally based split soleus muscle flap. British Journal of Plastic Surgery, 40 (1): p. 20-26, 1987.

6- Ponten B.: The fasciocutaneous flap: Its use in soft tissue defects of the lower leg. British Journal of Plastic Surgery, 34 (2): p. 215-220, 1981.

7- Koshima I., et al.: The vasculature and clinical application of the posterior tibial perforator-based flap. Plastic and Reconstructive Surgery, 90 (4): p. 643-649, 1992.

8- Tanaka K., et al.: An anatomic study of the intermuscular septum of the lower leg; branches from the posterior tibial artery and potential for reconstruction of the lower leg and the heel. Journal of Plastic, Reconstructive \& Aesthetic Surgery, 59 (8): p. 835-838, 2006.

9- Taylor G.I.: The angiosomes of the body and their supply to perforator flaps. Clinics in plastic surgery, 30 (3): p. 331-342, 2003.

10- Hallock G.G.: Lower extremity muscle perforator flaps for lower extremity reconstruction. Plastic and Reconstructive Surgery, 114 (5): p. 1123-1130, 2004.

11- Schaverien M. and M. Saint-Cyr: Perforators of the lower leg: Analysis of perforator locations and clinical application for pedicled perforator flaps. Plastic and Reconstructive Surgery, 122 (1): p. 161-170, 2008.

12- Georgescu A.V., et al.: Microsurgical nonmicrovascular flaps in forearm and hand reconstruction. Microsurgery, 27 (5): p. 384-394, 2007.

13- Acland R., et al.: The saphenous neurovascular free flap. Plastic and reconstructive surgery, 67 (6): p. 763-774, 1981.

14- Hyakusoku H., T. Yamamoto and M. Fumiiri: The propeller flap method. British Journal of Plastic Surgery, 44 (1): p. 53-54, 1991.

15- Wei F.C. and S. Mardini: Free-style free flaps. Plastic and reconstructive surgery, 114 (4): p. 910-916, 2004.

16- Yildirim S., G. Taylan and T. Aköz: Freestyle perforatorbased VY advancement flap for reconstruction of soft tissue defects at various anatomic regions. Annals of plastic surgery, 58 (5): p. 501-506, 2007. 